\title{
An Interoperable BIM-Based Toolkit for Efficient Renovation in Buildings ${ }^{\dagger}$
}

\author{
Bruno Daniotti ${ }^{1, *}$, Cecilia Maria Bolognesi ${ }^{1}{ }^{\mathbb{D}}$, Sonia Lupica Spagnolo ${ }^{1} \mathbb{D}$, Alberto Pavan ${ }^{1}$, Martina Signorini ${ }^{1}$, \\ Simone Ciuffreda ${ }^{1}$, Claudio Mirarchi ${ }^{1}\left(\mathbb{D}\right.$, Meherun Nesa Lucky ${ }^{1}$, Birgitta Andersson ${ }^{2}{ }^{\circledR}$, Per Andersson ${ }^{3}$, \\ Alessandro Valra ${ }^{4}$, Davide Madeddu ${ }^{4}$, Jacopo Chiappetti ${ }^{4}$, Diego Farina ${ }^{4}$, Brian O'Regan ${ }^{5}$ (D, Eoin O'Leidhin ${ }^{5}$, \\ Farah Tahir ${ }^{5}$, Karen Mould ${ }^{5}$, Stephen O'Donovan ${ }^{6}$, Sinead O'Sullivan ${ }^{6}$, Andriy Hryshchenko ${ }^{6}$ (i) \\ and Dominic O'Sullivan ${ }^{6}(\mathbb{D}$
}

check for

updates

Citation: Daniotti, B.; Bolognesi, C.M.; Lupica Spagnolo, S.; Pavan, A.; Signorini, M.; Ciuffreda, S.; Mirarchi, C.; Lucky, M.N.; Andersson, B.; Andersson, P.; et al. An Interoperable BIM-Based Toolkit for Efficient Renovation in Buildings. Buildings 2021, 11, 271. https://doi.org/ 10.3390/buildings11070271

Academic Editors: Miimu Airaksinen and Isabel Pinto Seppä

Received: 14 May 2021

Accepted: 22 June 2021

Published: 25 June 2021

Publisher's Note: MDPI stays neutra with regard to jurisdictional claims in published maps and institutional affiliations.

Copyright: (c) 2021 by the authors. Licensee MDPI, Basel, Switzerland. This article is an open access article distributed under the terms and conditions of the Creative Commons Attribution (CC BY) license (https:// creativecommons.org/licenses/by/ $4.0 /)$
1 Department of Architecture, Built Environment and Construction Engineering, Politecnico di Milano, Via G. Ponzio 31, 20133 Milan, Italy; cecilia.bolognesi@polimi.it (C.M.B.); sonia.lupica@polimi.it (S.L.S.); alberto.pavan@polimi.it (A.P.); martina.signorini@polimi.it (M.S.); simone.ciuffreda@polimi.it (S.C.); claudio.mirarchi@polimi.it (C.M.); meherunnesa.lucky@polimi.it (M.N.L.)

2 RISE Research Institute of Sweden, Lindholmspiren 7 A, 41756 Göteborg, Sweden; birgitta.dm.andersson@gmail.com

3 CGI, Birkarlagatan 12, 98236 Gällivare, Sweden; per.e.andersson@cgi.com

4 One Team srl, Via Giovanni Gioacchino Winckelmann, 2, 20146 Milan, Italy; alessandro.valra@oneteam.it (A.V.); davide.madeddu@oneteam.it (D.M.); jacopo.chiappetti@oneteam.it (J.C.); diego.farina@oneteam.it (D.F.)

5 International Energy Research Centre, Tyndall National Institute, Lee Maltings Complex Dyke Parade, T12 R5CP Cork, Ireland; brian.oregan@ierc.ie (B.O.); eoin.oleidhin@ierc.ie (E.O.); farah.tahir@ierc.ie (F.T.); karen.mould@ierc.ie (K.M.)

6 School of Engineering, University College Cork, Gaol Walk, T12 YN60 Cork, Ireland; s.p.odonnabhain@umail.ucc.ie (S.O.); sineadisullivan@gmail.com (S.O.); a.hryshchenko@ucc.ie (A.H.); dominic.osullivan@ucc.ie (D.O.)

* Correspondence: bruno.daniotti@polimi.it

† Presented at the Sustainable Places 2020 (SP 2020), Digital Event, Italy, 27-30 October 2020.

Abstract: Since the buildings and construction sector is one of the main areas responsible for energy consumption and emissions, focusing on their refurbishment and promoting actions in this direction will be helpful to achieve an EU Agenda objective of making Europe climate-neutral by 2050. One step towards the renovation action is the exploitation of digital tools into a BIM framework. The scope of the research contained in this paper is to improve the management of information throughout the different stages of the renovation process, allowing an interoperable exchange of data among the involved stakeholders; the development of an innovative BIM-based toolkit is the answer to the research question. The research and results obtained related with the development of an interoperable BIM-based toolkit for efficient renovation in buildings in the framework of the European research project BIM4EEB. Specifically, the developed BIM management system allows the exchange of the data among the different tools, using open interoperable formats (as IFC) and linked data, in a Common Data Environment, to be used by the different stakeholders. Additionally, the developed tools allow the stakeholders to manage different stages of the renovation process, facilitating efficiencies in terms of time reduction and improving the resulting quality. The validity of each tool with respect to existing practices is demonstrated here, and the strengths and weaknesses of the proposed tools are described in the workflow detailing issues such as interoperability, collaboration, integration of different solutions, and time consuming existing survey processes.

Keywords: renovation; BIM; BIM tools; interoperability; digitalization; ICT; linked data

\section{Introduction}

Data on energy consumption and emissions highlight that the AEC sector (Architecture, Engineering, and Construction) is one of the major responsible areas $-40 \%$ of the 
EU's energy consumption and 36\% of greenhouse gas emissions from energy [1]. If we consider that only $1 \%$ of buildings are undergoing renovations interventions to become more energy-efficient, it is fundamental to adopt strategies in this direction. The most relevant obstacles to overcome for the sustainability goals in the housing building sector are: the quality of renovations, the timing of such processes, the impact on tenants, and the consequent inconvenient cost-benefit trade-offs. In addition, issues in accessing information arise especially when information is mostly in a paper-based format and when stakeholders are numerous.

Hence, the renovation can be considered as a big challenge for the building sector. The digitalization could help towards the improvement of building efficiency, sustainability, and decarbonization. Enhancing data and information share, as well as communication among several parties, enables the application of testing and surveying methods [2].

Digital tools can seamlessly connect different stakeholders such as architects, engineers, services, and contractors during the building lifecycle from the design to operation phase.

BIM (Building Information Model) allows for the storing and sharing of information with the relevant people helping to avoid uncertainties and errors, and the contributing to building process optimization.

The more efficient use of resources and a more effective communication and collaboration within the design team could lead not only to an improved building process but also to an improved renovation process. Despite the claimed benefits, BIM implementation is still hindered by issues of various origin: socio-historical [3], technological [4], and organizational [5] reasons. Moreover, a critical success factor for BIM is interoperability, i.e., the ability to reuse information among different software tools and platform. This issue emerges as difficult access to building data, lack of support between authored file formats, the absence of integration between software solutions, or underestimation of lifecycle issues [6]. Achieving interoperability is the goal of BuildingSMART, the organization responsible for the development of IFC (Industry Foundation Classes), the vendor neutral data exchange format, described as the industry standard in ISO 16739.

Generally, in the AEC sector, the information sharing occurs and lays in the CDE concept (Common Data Environment), namely a repository such as a project extranet or electronic document management system or as later updated as a single source of information for any given project, used to collect, manage, and disseminate all relevant approved project documents for multi-disciplinary teams in a managed process [7].

One of the technologies that researchers have been using to face the issues of knowledge representation and interoperability is Semantic Web. The development of solutions following Semantic Web principles is mainly motivated by improving the information exchange between tools of different AEC disciplines, effectively connecting different domains of construction lifecycle and exploiting the inference capabilities of Linked Data [8].

Within this context, the research developed by BIM4EEB (BIM4EEB: BIM based fast toolkit for Efficient rEnovation of residential Buildings), a European Horizon2020 project, has produced as an outcome a series of BIM-based tools for enhancing the renovation building process: an interoperable toolkit that supports the weaknesses of the traditional renovation of buildings. This paper attempts to answer a clear and defined research question: Can BIM become a useful methodology where digital tools improve the renovation processes of buildings to decrease energy consumption to achieve the objectives of the EU agenda? In addition, if so, how and what are the difficulties in this process? In this paper, processes and products aiming at this objective are outlined. Issues met to obtain different interoperable BIM-based solutions, connected through an IFC-based BIM Management system, are presented.

After the adopted methodology, a specific chapter is dedicated to the presentation of the results as for the BIM based toolkit, with a specific focus on the developed BIM Management system and on some specific new tools. 
Finally, the ongoing and future developments as for testing and the demonstration on specific case studies and conclusions are highlighted.

This paper is composed as follows: The introduction includes a description of the background of the renovation of residential buildings and the main obstacles; Section 2 introduces the methodology of the research and the preliminary stages of development of a BIM-based toolkit; Section 3 presents the toolkit development, starting from its principal component, the BIMMS (BIM Management System), and covering all the developed tools; Section 4 presents the real environment demonstration for the testing and validation procedure; and, finally, Section 5 includes a final overview and the future developments.

\subsection{Background}

The construction sector has increasingly adopted the use of BIM to increase productivity and quality in building and infrastructure projects, to reduce financial losses during construction. On the other hand, the renovation of the built environment is a topic that must also be addressed, given that existing buildings are the principal accountable for emissions and energy consumption. In the following part of this paragraph, the most relevant issues related to the renovation interventions and the interoperability question connected to the use of BIM are presented.

\subsection{Common Barriers in Renovation}

Among the principal objectives of the research is to assist in the pathway that existing buildings will consume less energy and release less $\mathrm{CO}_{2}$ towards the goal of climate neutrality, and to improve the comfort of inhabitants who are in unhealthy homes. This results in an increase in the practice of renovating and re-using buildings $[9,10]$. However, a consistent number of issues need to be faced. These can be classified in the following main groups [11,12]:

- Technical barriers

- Financial barriers

- Legislative and Regulatory barriers

- Social barriers

Technical barriers regard: the complexity and variety of buildings and a relative lack of consistent and standardized solutions or integrated solutions and a lack of skilled workers to carry out the work; the lack of awareness about what to do and in which order for improving building conditions and about the advantages of different renovation scenarios; while referring to operation and maintenance, collected data during design stages is generally not used nor updated after the construction stage, and, if available, it is in a paper-based format and then difficult to be accessed.

Financial barriers include a general difficulty in accessing finance due to insufficient available funding, long pay-back times of renovation interventions, and high upfront costs.

Obstacles are also related to legislative and regulatory aspects, considering local laws and regulations to be specifically applied in renovation processes and a lack of a legislative framework such as government programmes/actions that does not encourage deep renovation.

Social aspects must be considered too. Lack of awareness of the benefits of retrofitting or a lack of interest in energy efficiency as well as a lack of communication and mutual understanding among the involved professional disciplines in a project are included in this category.

Hence, renovation is one of the biggest challenges for the building sector. One step to overcome these obstacles towards the improvement of buildings efficiency is the exploitation of digitalization [13].

\subsection{Interoperability}

Interoperability is seen as a key success factor for the implementation of such technologies, both from the point of view of different actors and disciplines and from the point 
of view of the ICT (Information and Communication Technologies) tools. In the last decade, the Semantic Web application in the AEC industry has been the main goal of relevant research efforts because of the promise to ease communication issues and help the use of web-based and BIM-based systems [14].

The most relevant effort to facilitate information exchange among different platforms and disciplines is the Industry Foundation Classes (IFC). It is composed of a set of standards identifying a data schema (IFC), data exchange specifications as Model View Definitions (MVDs), neutral communication protocols such as the BIM Collaboration Format (BCF), a standard library of BIM object definitions (bSDD), and, finally, a data exchange protocol for stakeholder of construction processes. The current version of ISO 16739:2018 standard refers to the IFC4 ADD2 TC1 schema.

One of the perspectives of using Semantic Web technologies is to link different disciplines for lifecycle management of buildings, e.g., using technologies such as AR (Augmented Reality) for the creation of BIM models, BACS (Building Automation and Controls Systems), on-site activity tracking, and other tools that need a good level of interoperability to accelerate construction processes [15]. The project of ifcOWL [16], the OWL (Web Ontology Language) representation of the IFC schema, is proposed as the building domain ontology as a translation of the EXPRESS IFC schema.

The main drawback of the deployment of Semantic Web technologies for AEC (Architecture, Engineering, and Construction) in resolving interoperability issues is that, although linked data can technically provide efficient solutions for such problems, both agreement on standard formats between construction professionals and consistent manual adjustment for ontologies' development and alignment are needed to reach full interoperability [8].

Relevant examples of the application of these technologies in $\mathrm{H} 2020$ projects are HESMOS [16], which developed a modelling framework based on open standards for the efficient energy design for new buildings; SWIMing [17], a project developing a BIM cloud using Linked Open Data; STREAMER [18], aiming at reducing the energy use and carbon footprint by offering optimized Semantic-driven design methods and interoperable tools for BIM and GIS (Geographic Information Systems).

\section{Methodology}

This paragraph shows the followed procedure for the realization of BIM-based tools aimed at overcoming issues related to renovation and to interoperability coming from BIM use. The working schema for the realization of the BIM toolkit is illustrated in Figure 1:

1. In a broad panorama such as that of renovation, there are many and different stakeholders who communicate and collaborate. Therefore, initially it is necessary to define every activity required in each stage of a renovation process, to outline the involved stakeholders in the different stages, and to define the most proper information exchange process in what authors called the renovation process map [19].

2. Consequently, stakeholders' needs and requirements to be satisfied during renovation interventions are individualized. These could be divided into major groups: designers, construction companies, service companies, building owners, and inhabitants.

3. At this point, the analysis allows for ensuring the best adaptation of the methodological and technological features of the BIM-based toolkit to the specific needs. For example, a fast-mapping tool has been developed to answer to the need of speeding up the survey process and improving quality; a digital logbook instead wants to avoid lack of information or an incomplete knowledge about building information that are typical renovation barriers.

4. The necessity for a connection among the different tools and the necessity to meet the need for interoperability lead towards the development of a BIM Management system to coordinate all of them.

5. Finally, case studies will be used to verify and test the validity of the developed BIM-based toolkit. 


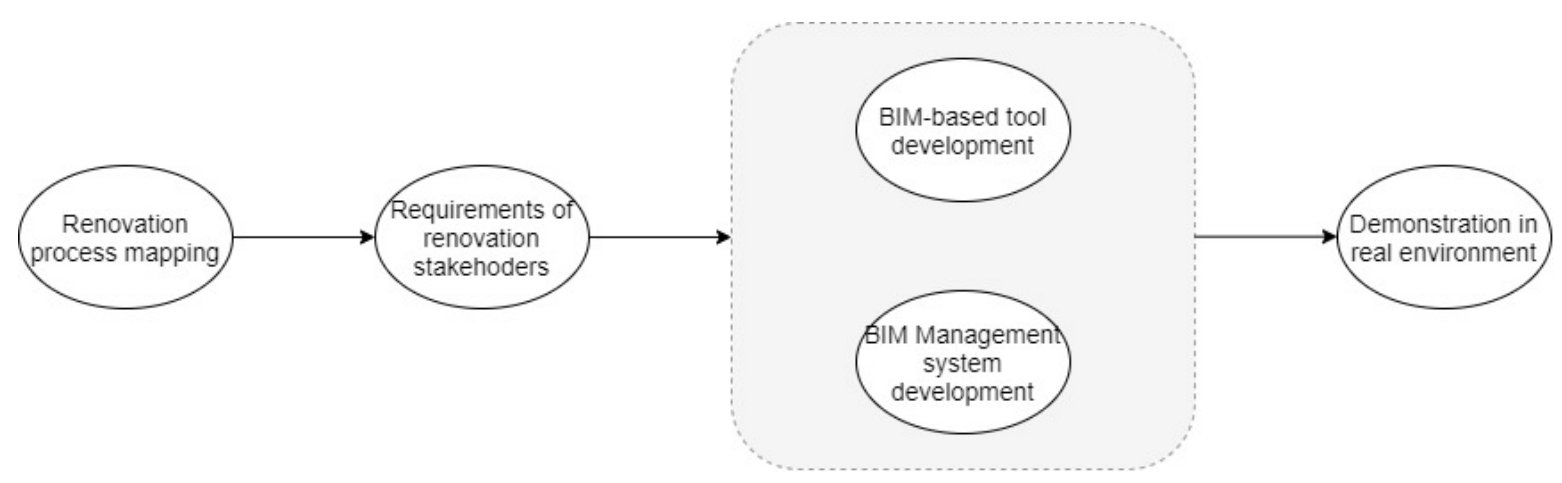

Figure 1. Research methodology.

3. Results: The BIM4EEB Interoperable BIM-Based Integrated Toolkit for Buildings' Renovation

Unlike industrial products, buildings are results of custom design processes over specific environmental, economic, and use conditions. The first part of this research consists in gathering existing information and standards about construction stages and stakeholders, and their activities during such stages.

The definition of standard workflows has always been in the interest of researchers, professionals, and local authorities.

The existing standard EN 16310:2013 [20] has been analyzed with the goal of defining activities and processes in which an optimization could be applied, e.g., by applying a BIM-based tool improving information management.

The main actors of renovation processes, divided into the macro-categories of designers, construction companies, service companies, owners, and inhabitants, have been asked about their requirements and activities through dedicated surveys. These results show that building operation professionals suffer the most in the lack of available information about buildings and those designers highlighting the need for collaborative design tools in order to face all the economic, comfort, operational, and environmental challenges of renovation [21,22]. From the occupants' and owners' points of view, an increase in communication with construction companies and service operators is needed, considering the case scenarios highlighted in the analysis [23].

The result of the research is translated into a BIM-based toolkit involving different stakeholders of the construction sector with the aim to increase the adoption of BIM in the renovation businesses based on an interoperable flow of information. The toolkit developed within the BIM4EEB project is composed of different tools as different answers to different necessities of the renovation process; they are connected to a BIM management system (BIMMS) (Figure 2).

The BIM Management System platform and different tools developed serve the business functionalities. The six BIM-based tools developed are the following:

1. BIM Management System

2. A tool to support decision-making and energy refurbishment assessment

3. A BIM assisted Energy refurbishment assessment tool

4. A human machine interface tool

5. A fast-tracking tool for renovation operations

6. A tool for reducing the survey time

The so-called Digital Logbook has been provided too and was included into the BIM Management System. It is not a mere BIM tool, but the idea is to digitalize and collect all the data and information related to the building and contained in a logbook within a CDE represented by the BIM Management System. 


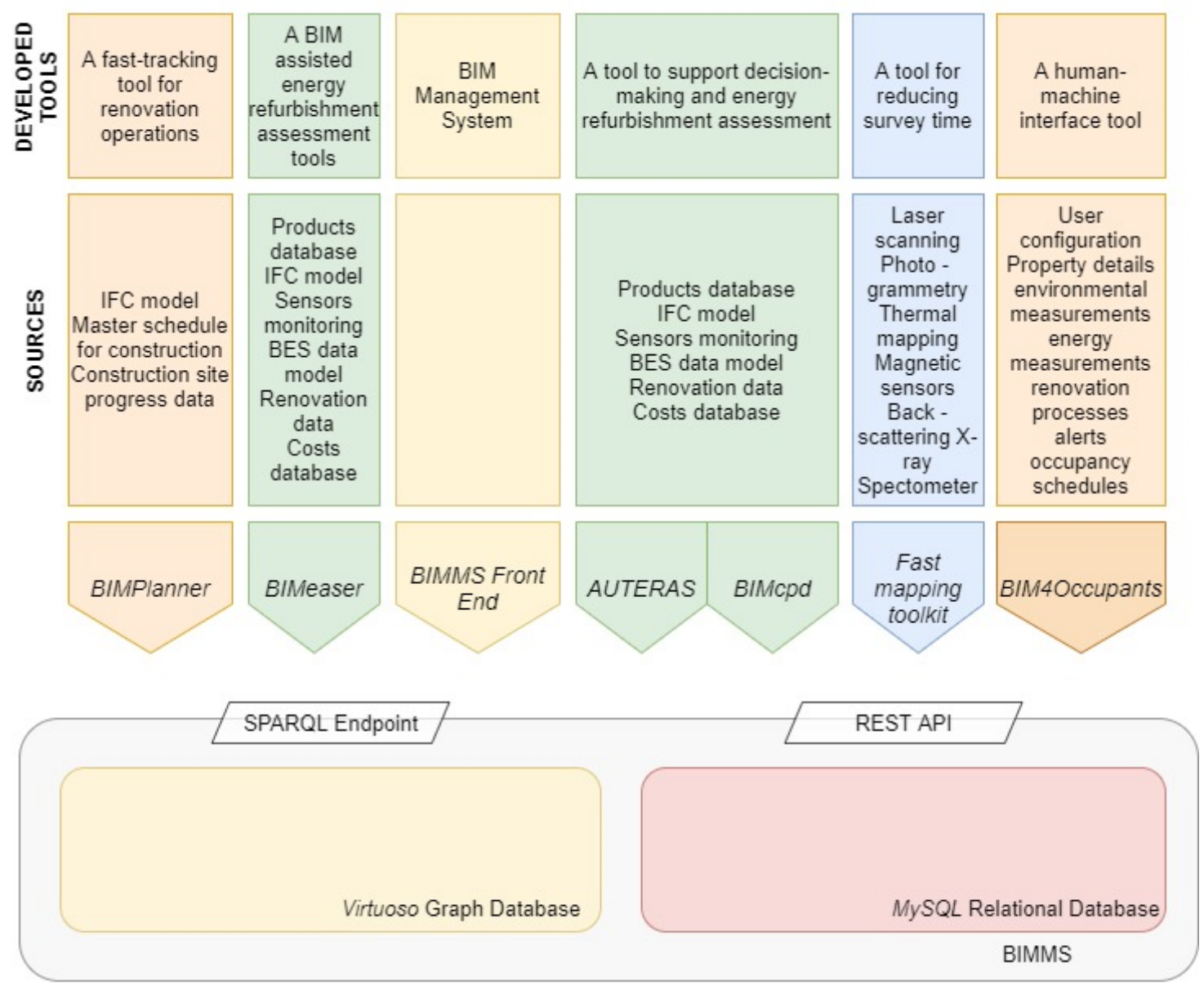

Figure 2. General overview of the BIM4EEB toolkit.

In the following paragraphs, firstly a description of the BIM Management System and its principal functionalities are outlined, and then the BIM-based tools developed are described.

\subsection{The Digital Logbook}

In the renovation process, different types of information and data are exchanged between stakeholders contributing to limits such as lack of communication or improper exchange of information. To overcome these barriers, a digital logbook has been developed. It can be conceived as building-related information such as energy analysis, maintenance, and operation, and it can be used as a bilateral tool that allows connecting users and third parties, fulfilling service companies' needs and requirements [24,25].

The logbook has been developed in a digital format; hence its name, it is stored within the BIM Management System, and it could be accessed directly from it. The particularity and effectiveness of this instrument is dictated by the fact that it is accessible to all participants of the renovation process, according to different degrees of authorization owners, inhabitants, designers, facility managers, public authorities, etc. who can access, analyze, and add information and data related to the specific building.

On the other side in this way, it is possible to have a continuous monitoring of the information and consequently of the building itself, avoiding inconsistencies between building operation and building design. In addition, inhabitants will be able to see closely that which is the design purpose and building performance enhancing comfort, quality, and productivity. 


\subsection{An Open CDE Based on Linked Data}

This section describes how different IFC-based tools for different stakeholders among a building renovation lifecycle can contribute to the realization of a BIM Management System (BIMMS) to reply to improvements of the renovation research.

In Figure 2, a general overview of the tools composing the toolkit and their relation is presented. The flow of information from different sources is represented by the arrows going from left to right, as sources are considered the techniques, the databases, or the processes that provide input to the tools. The output from each tool is then uploaded or made available to the BIMMS through SPARQL (recursive acronym for SPARQL Protocol and RDF Query Language) queries. File formats are specified for every information exchange.

The BIMMS platform is acting as the data management layer of the BIM4EEB platform that links, converts, and stores data from heterogeneous data sources in the building environment. On top of the BIMMS platform, the tools are developed as independent applications with their respective front-ends (User Interfaces), interchanging data with the BIMMS platform but also with third-party data sources and applications.

The research compels the formulation of a CDE that acts as a deposit for all the information and data collected throughout the entire building lifecycle, acting as a single source of truth (SSOT). The main functions of the BIMMS and its CDE are storing, sharing, and visualizing BIM models but also managing documents and energy performance data. All the data is then shared and can be accessed with pre-established rules, and it can be traceable thanks to the historical records and revisions. As defined in the Semantic Web technology, all the contents of the CDE will be considered resources using the Resource Description Framework (RDF). Figure 3, inspired by the work of Curry et al. [26], shows the proposed approach for the use of RDF resources integrating different data sources. The proposed solution for the CDE allows the conversion of EXPRESS-based IFC files and other metadata in RDF, enabling semantic interoperability through the use of a framework of ontologies [27]. An IFC editor integrated in the CDE is proposed in the BIMMS to make the process circular, as shown in Figure 3.

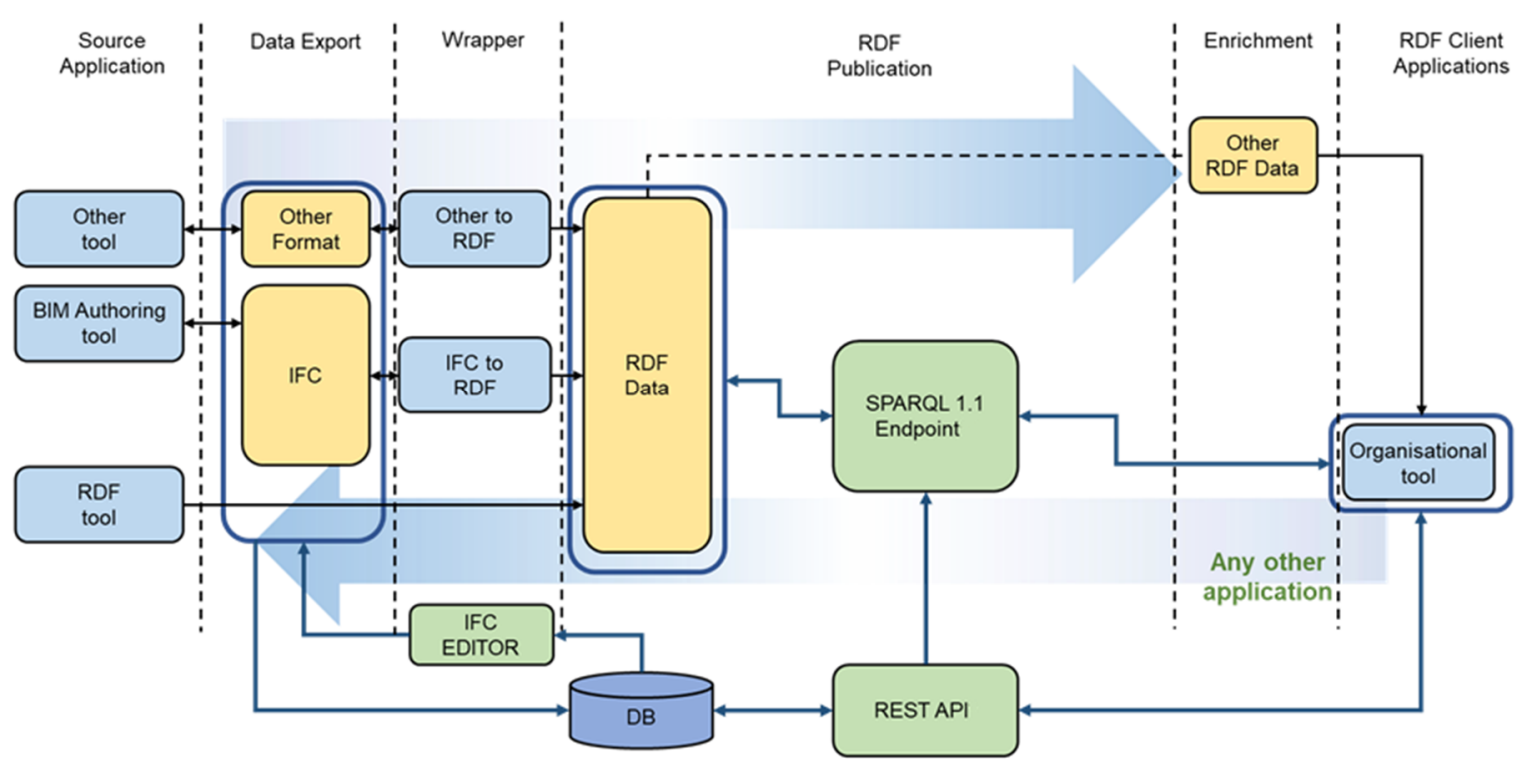

Figure 3. Approach of the proposed BIM Management System.

Users can create, view, and download the resources and data stored in the CDE. To define a resource, users can use a wizard tool that allows them to upload a file, add a description, and map with other existing resources. The resource can also be integrated with Linked Data by selecting the domain, properties, and value of one or more available ontologies in the BIMMS. 
The resource management contains a specific section that lists all the BIM Models in the project with links to download the original format and in the RDF ifcOWL [28] or BOT (Building Topology Ontology) [27] ontologies. The RDS files are created by the BIMMS conversion functionalities and are available to exploit the IFC data in the Linked Data context.

Another functionality of the BIMMS, related to the Exchange Layer, is the SPARQL Endpoint, which can receive and process SPARQL Protocol requests [29]. Once the resources are uploaded in the CDE, enabled users can search and filter the information according to specific data connected to the resource itself. Through the SPARQL language [30], the endpoint enables users and applications to query a knowledge base. A well-formed query can retrieve data across different domains and repositories, allowing relationships to be made beyond the information available in the BIMMS.

The Ontology viewer allows the transformation into a graphical form of the ontology data stored into the BIMMS thanks to a web graphic visualization. This way, it will be easier to see how data are linked together. This tool is useful to explore the richness of semantic nets and to create graph layouts of resources.

As for the last tool, the Interoperability and Exchange Layer service is used to access data by external tools, and it works as an interface between applications and the CDE. REST principles [31] are used to integrate tools and services in the Interoperability and Exchange Layer Services exposing a set of APIs (Application Programming Interfaces) on the BIMMS Web Portal under the Endpoints, which are available upon registration on the BIMMS [32].

There are two different databases which implement the CDE: a relation DBMS (Database Management System), SQL-based as MySQL, and a hybrid ODBMS (Object Database Management System) that supports RDFs to triple store as Openlink Virtuoso. Working as middleware with a hybrid database engine, the chosen triple store platform supports the semantic web of data and extends, through live linking, the existing data on the relational DBMS, and, hence, the entity relationships will extend beyond SQL tables to RDF graphs allowing reasoning and inferences rules performed by Virtuoso Platform also on MySQL data.

The MySQL DBMS is used as data storage that manages all the 3D BIM Models, documents, drawings, and data streaming. Furthermore, MySQL manages the website's backend with tables and views to manage interface, users, and roles management. The Virtuoso Platform is used as a storage for linked data resources that are directly uploaded as RDS, triples creation and modification, geo-linked data store and resource graphs and ontologies. The platform is configured to enable SPARQL queries through the Virtuoso SPARQL Endpoint available in the BIMMS Web Portal.

As for the 3D BIM Models, they are stored and shared in the CDE through the IFC file format. When an IFC Model is uploaded in the CDE, a process will start to parse the file and store all the items in the MySQL database. Once the model is processed, it can be viewed by the 3D Viewer and by the Virtuoso Linked Data View definition. The IFC items as Linked Data are then converted into the two most common ontologies that support IFC files: ifcOWL and Building Topology Ontology (BOT). The conversion is made through the open source IFCtoLBD converter [33].

The Virtuoso platform, thanks to the data access drivers, will access tables and views in the MySQL and will map entities, properties, and values that are linked in the data graph. Drivers connect both databases acting as a middleware that collects all the data on external databases without the additional costs of developing a specific data convertor for every need. This solution, on long-term use of the BIMMS, greatly improves the efficiency with an expected improved performance on big models' management since the file is not parsed on the fly, and it is not necessary to load the whole data before getting the results of complex queries. Moreover, MySQL can be used both as a file storage and to manage versioning, permissions, and user management. These charts and views are translated in RDF thanks to the capabilities of the R2RML module of the Virtuoso Server, a mapping 
language schema from relational data to RDF. Eventually, the BIMMS exposes the Virtuoso SPARQL Endpoint as an internal Endpoint under the SPARQL functionalities in the BIMMS web portal.

\subsection{Tool for Reducing the Survey Time}

Nowadays, many surveying and positioning devices lack interfaces and interoperability for collecting the data measured or lack shareable positioning systems. The research question comes from a necessity to reduce survey time implementing information coming from the mapping of buildings; a solution investigated is to create an IFC model rich of information such as hidden installations and materials in the wall directly with survey instruments helping saving time in the renovation process. The approach followed has been to be able to use devices and solutions starting from tools and software already available on the market, but which, in new couplings, can meet the needs of speed, accuracy, and survey of hidden parts.

This tool created consists of two parts: a sensor-stick and an AR device. The Sensor stick is developed for scanning the installations in the building and is completed by Hololens in the hardware part, which allows a virtual immersion. The workflow of the tool is described in the Figure 4 and starts from a point cloud generation previously acquired by a laser scanner. The installation inside the walls can be easily detached by sweeping the wall to cover most of the area using a HoloLens2 headset and manage the menus virtually at the same time.

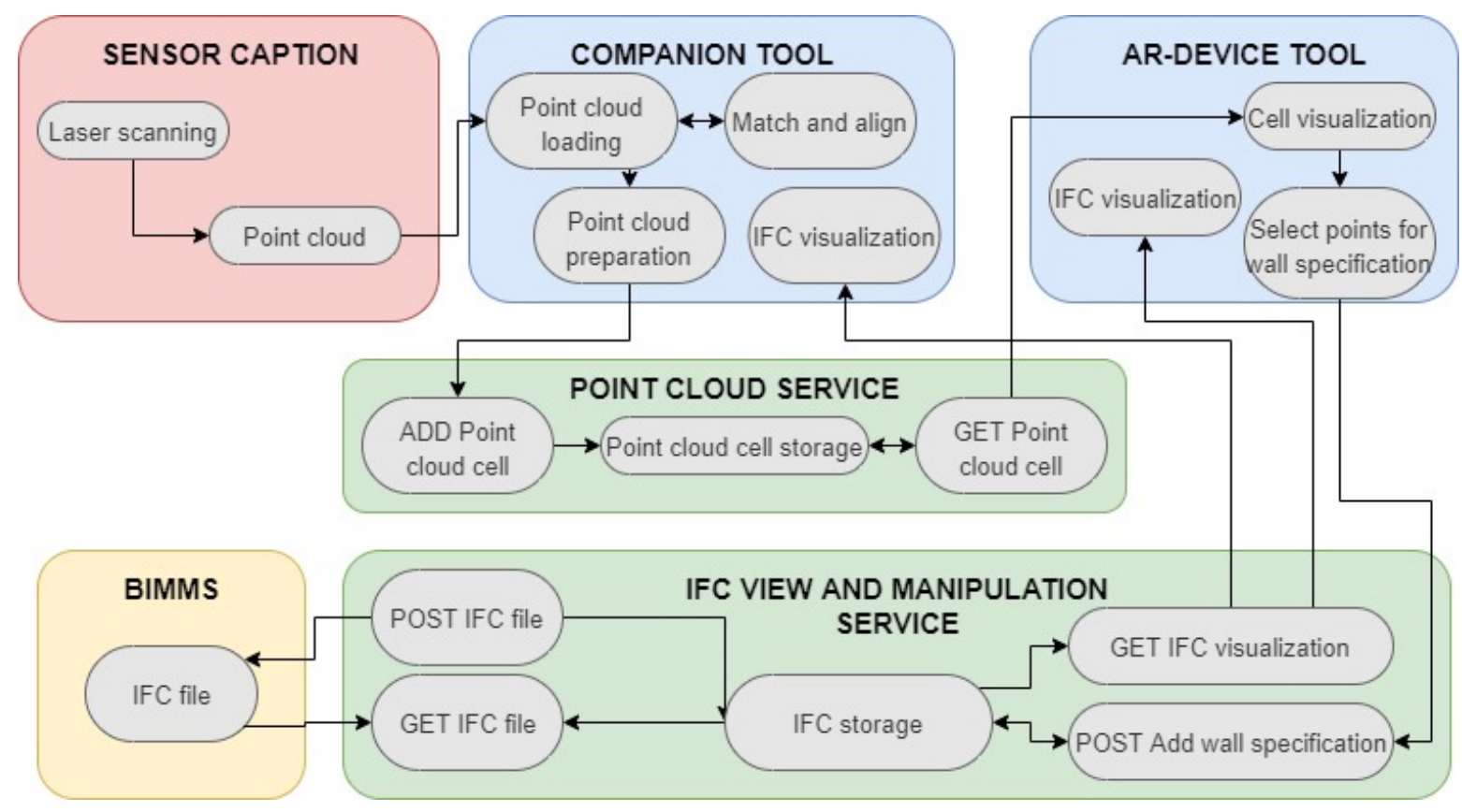

Figure 4. Workflow of the fast mapping of buildings.

To sum up, laser scanner data and sensors stick data are transformed in IFC Files to dialogue with the AR-tool; results of visualizing 3D-models in mixed reality were made by transferring data from scanning into an AR-tool and visualized in a HoloLens device; geometry and hidden installations were found by the sensor stick combined with the AR-tool; the generated IFC files have been transferred to the BIM management system.

\subsection{A Tool for Connecting BIM Models and BACS}

AUTERAS, which stands for AUTomated Engineering of Room Automation Systems, is a tool designed to manage room automation systems. It allows the creation of schemas and supports the selection of devices considering the constraints related to connections in 
the system. One of the major functionalities of AUTERAS is the capability of the creation of VDI 3813-2 compliant room control schematics, i.e., the tool allows the creation of a schema representing the devices, their roles, and their interaction in a technological-neutral and vendor-neutral specification.

Users are guided through the creation of room schematics thanks to a knowledgebased requirement tool that can support the choice of functions according to the context of the system. The schema is then generated and can still be modified manually by the user. At this stage, AUTERAS optimizes the schematics into room automation system designs. Considering the previous step, the model now includes the mapping of function blocks into real devices' functions and connections. A device database collects information about real devices' parameters in a machine-readable way. Data are stored in RDF format. The tool has a client interface which carries out calculations to external servers and communicates with BIMMS through the REST (Representational State Transfer) API [34].

\subsection{A Tool to Support Decision-Making and Energy Refurbishment Assessment}

The ability to measure savings made in terms of energy, money, and other factors such as $\mathrm{CO}_{2}$ can be invaluable in proving to people and businesses the benefits of energy efficient renovation of their buildings. BIM tools can ease the process of demonstrating positive effects of renovation operations, and, linking with other datasets, can make the design stages more efficient.

The proposed toolset contains several distinct intuitive applications that will allow the user to: (a) find recommended positions for HVAC, lighting, and other devices; (b) analyze data from sensors, energy bills, and other sources (weather, for example); (c) manage the data that they have on the above and create new data sets that they can share with other tools. The structure of the tool, named BIMcpd, divides into three interconnected components, i.e., " $\mathrm{c}$ "-Constraint Checking; " $\mathrm{p}$ "-Performance evaluation; " $\mathrm{d}$ "-Data Management.

These tools were designed to ensure minimum complications for the user while maximizing the outputs of each tool. The constraint checking tool (i.e., "c" part) is designed to include as many references to building regulations as possible, and calculations were made using recommended guidelines. The performance analysis tools (i.e., " $\mathrm{p}$ " part) were split into two separate modules: (a) data viewer-for viewing data uploaded in the data management module and apply outlier detection methods to the data; (b) Measurement and Verification $(\mathrm{M} \& \mathrm{~V})$ - for creating a baseline model of the building prior to the implementation of Energy Conservation Measures (ECM's) or building renovation, and comparison post-work and the creating of a reporting period model to calculate energy and other savings, in addition to applying non-routine adjustments to the reporting period. The data management tool (i.e., " $\mathrm{d}$ " part of the BIMcpd toolset) is designed to reduce the time consumed in data entry; it allows users to map data uploaded to our database schema and make the data immediately useable in the performance analysis tools.

The focus of the Constraint Checking Tool was the extraction of information from an IFC file (e.g., demo-site BIM model) and comparing it with data stored in the tool database, which will allow the values from the model to be checked to ensure they are compliant with existing building codes, such as fire or lighting regulations. The main output of that would be an on-screen (exportable) report which will highlight where the BIM model does not comply with the regulations and why it failed, for example: fire doors not compliant with those specific countries' building code.

The Performance Evaluation Tool is following with the Measurement and Verification $(\mathrm{M} \& \mathrm{~V})$ process and principles [35], while allowing data uploaded by the user to be modelled. A baseline model can be created (prior to the renovation work being carried out), and a reporting period model can be created (after the renovation work is carried out).

In the Data Management Tool, data model type is chosen by a user, with Simple Linear Regression (SLR), Change Point Regression (CPR), and SLR/CPR with Filtering. Data can also be viewed independently (i.e., not modelled with other data) and displayed in a variety of formats. In addition, data can be manipulated, such as data filtering and 
outlier identification. Non-routine adjustments [36] can also be applied to the reporting period model, allowing users to indicate a change in circumstances between the baseline and report modelling periods (such as change in occupancy of the building). All data uploaded in this Data Management Tool are accessible in the Performance Evaluation Tool mentioned above. The data is saved to a MySQL relational database consisting of an extensive list of potential data types, which will allow a large variety of data to be saved, thus future proofing the tool. Data tags are provided to be applied to all data uploaded into the database; for now, this is consisting as the list of $\sum 229$ data tags [37]

The BIMcpd toolset consists of a responsive web-based software application constructed on the Bootstrap 3 Framework and includes a secure user registration/login system. The tools developed in the BIMcpd set will include PHP, JavaScript, jQuery, Python, MySQL, and JSON.

\subsection{A BIM Assisted Energy Refurbishment Assessment Tool}

Dealing with renovation, there is a need for the performance-based building design during the early phases of the design, when important decisions are made according to costs and performance to guarantee owners' and users' satisfaction and the quality of design. Concerning the energy performance aspect, generally a dynamic simulation coupled with the BIM and detailed information about technical building systems are used. A BIM-assisted scenario simulator has been integrated to support energy-related decision-making in a retrofitting process when the enriched BIM models are available.

The developed tool, namely BIMeaser, is an early-stage design tool aiming at validating design scenarios [38]. Due to the connection with commercial simulation tools, energy requirements and indoor environmental conditions can be easily evaluated and optimized describing different scenarios. The workflow of this tool starts from the BIM Management System which provides the building model for the energy simulation (Figure 5). Then, this model can be imported in the BIMeaser web application, hosted on the web server Apache Tomcat, and validated according to sets of energetic, comfort, and economic indicators. Models can be enriched through the integration of data from national renovation measure databases. The results of the analysis are stored in triple stores so that they return to the BIM Management System.

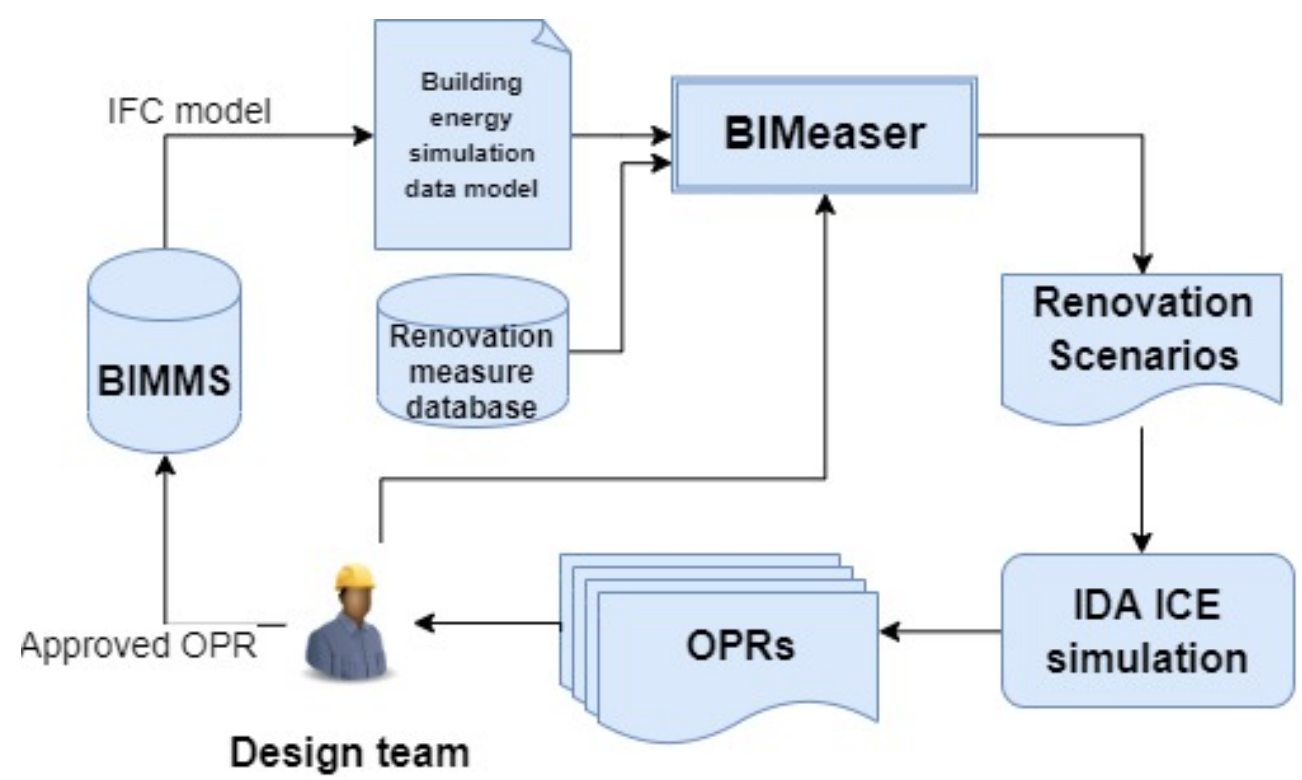

Figure 5. Workflow of the BIMeaser tool.

The tool allows a precise build-up of the models and scenarios thanks to the integration with the BIM Management System. On the other hand, the accuracy of the tool is related to 
the quality and precision of the BIM models submitted. If a model lacks information, or if such information is distant from reality, the results would be incoherent with the results of the design process. Moreover, the required time for the simulations may vary according to the quality issues of the models.

\subsection{Human Machine Interface Tool}

Renovation operations, unlike traditional new construction processes, take place in existing buildings, which are usually occupied. This creates a need for a tool for communication between tenants, building owners, and the other stakeholders of renovation.

BIM4Occupants, the proposed solution, is designed to tackle the issues of communication between building occupants and renovation stakeholders as it offers a web-based platform for these two parties. As the other tools in BIM4EEB toolkit, the information sharing layer is based on Linked Data technologies using, among the others, the Digital Construction ontology suite (DICO) [39], developed for BIM4EEB.

The main focus of the tool is the role of occupants as primary actors of the construction process: As users interact through the platform, designers can capture needs and requirements of building users in order to plan activities, exchange safety alerts, and report alteration to the schedule or other issues. Two different versions of the application are available: one for building occupants and one for building owners. These two versions reflect the role-based framework of the BIM4EEB toolkit, ensuring both high-quality information and privacy for the operators.

\subsection{A Fast-Tracking Tool for Renovation Operations}

Communication and collaboration problems in renovation operations also involve designers and constructors, as existing buildings are characterized by more risks, different logistical requirements, and, possibly, more conflicts. Static planning of works made by different actors of a construction site can easily generate clashes if not well coordinated, revealing themselves inefficient.

The proposed software solution is a web-based tool for the fast track of renovation activities in housing buildings. The tool is designed to support communication of schedules and activities on a georeferenced basis, allowing stakeholders to understand better when and where activities are planned. The workflow is designed according to the Lean Construction principles [40].

In its application, this tool uses BIM models to define work locations. Since the BIM models are recalled from platforms of the toolkit, it is possible to coordinate the tools and inform occupants or other users about activities and safety issues. Thanks to the tools, contractors are able to schedule activities on site in specific places, thanks to the work locations, which are specific to individual tasks. In this way, it is possible to track timings and issues of any task by location, resulting in a precise control of the work progress and eventual deviations.

BIMPlanner is the name given to the result and has a browser-based interface with data stored in a graph database in RDF format according to DICO [41] and ifcOWL ontologies [42].

\section{Discussion}

The introduction of vendor-neutral software solutions to traditional renovation processes of residential buildings represents a challenge as new technologies such as Linked Data have limited application in the real environment. Typically, construction companies struggle to adopt new technologies, hindering the innovative potential of such tools. For these reasons, it is important to monitor the real use of developed tools in real environment, in order to highlight strengths and weaknesses of innovative software solutions. 


\subsection{Demonstration Sites}

The BIM Management System and the developed tools will be validated in three demonstration sites-Italy, Poland, and Finland-representing common building types in their areas. In addition to being placed in different climate areas, they have different building construction technologies, and they are in a socio-economic and culturally different context, as well as they have different objectives within the project. In Italy, the demonstration site is in Monza, a town in northern Italy. The residential building, belonging to the public housing managed by the partner ALER VCMB (ALER Varese-Como-Monza e Brianza-Busto Arsizio), has 9 floors with a total of 65 apartments, and it has been built in 1978. Polish demonstration site placed in Chorzow, a town in the southern Poland, covers 5 floors with 12 apartments and 3 areas, on the ground floor, for commercial purpose, and it was built in 1902. Finally, in Tampere (Finland), the third pilot site is located. It is a residential building built in 1998 and owned by YH kodit characterized by two buildings with 5 floors and 52 apartments.

In the Figure 6 below, the three demonstration sites are represented.

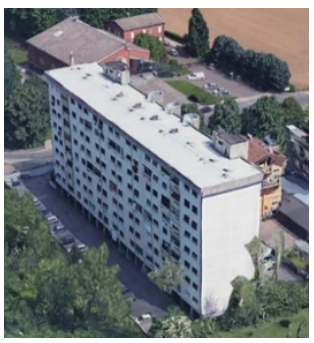

(a)

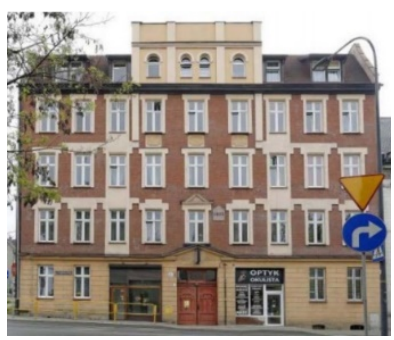

(b)

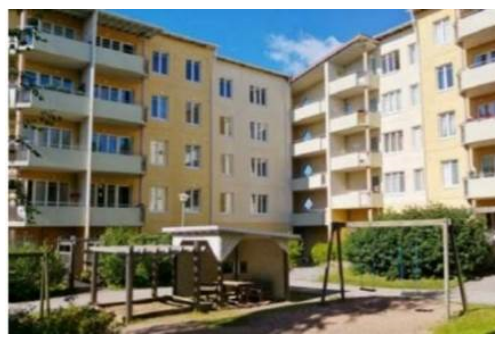

(c)

Figure 6. Demonstration sites chosen for the validation of the BIM4EEB developed tools. (a) Italian pilot site; (b) Polish pilot site; (c) Finnish pilot site. All photos are taken from the Grant Agreement of BIM4EEB project.

To test and validate the developed toolkit, tools will be applied to each demonstration site as indicated in the Table 1.

Table 1. Tools application on demonstration sites.

\begin{tabular}{cccccc}
\hline Demo Site & $\begin{array}{c}\text { BIM Management } \\
\text { System (BIMMS) }\end{array}$ & $\begin{array}{c}\text { Fast Mapping of } \\
\text { Buildings Toolkit }\end{array}$ & BIMeaser & BIM4Occupants & AUTERAS \\
\hline Italian & $\mathrm{x}$ & $\mathrm{x}$ & $\mathrm{x}$ & $\mathrm{x}$ & $\mathrm{x}$ \\
Polish & $\mathrm{x}$ & $\mathrm{x}$ & - & $\mathrm{x}$ & $\mathrm{x}$ \\
Finish & $\mathrm{x}$ & $\mathrm{x}$ & $\mathrm{x}$ & - & $\mathrm{x}$ \\
\hline
\end{tabular}

\subsection{Testing and Validation}

For the testing and validation purpose, various sensors were installed in specific apartments and rooms depending on residents' availability, diversification due to their exposition, and the technical condition of individual apartments, to monitor:

- Thermal and visual comfort such as temperature, relative humidity, occupancy, luminance;

- Indoor air quality, i.e., $\mathrm{CO}_{2}$;

- $\quad$ Electric power consumption, i.e., electricity meter;

- Gas consumption, i.e., gas meter.

It was established to install hardware in demonstration sites and a relative hardware topology to address the requirements mentioned. Furthermore, to collect sensors data, a system gateway, chosen due to its capability of integrating several sensors and devices systems, was introduced, and, thanks to the connection to its API, the related information will be gathered within the BIM Management System.

After the installation of sensors and gateway, the level of achievement of a specific objective by a tool will be examined with respective KPIs (Key Performance Indicators). 
Among the categories in which KPIs are divided, there are: Renovation Process KPIs, Energy Performance KPIs, Human Comfort KPIs, Economic Performance KPIs, Social Related KPIs, Environmental and Safety KPIs evaluating objectives and stakeholders' requirements fulfillment.

\section{Conclusions}

The paper presents the results related with the development of an interoperable BIM-based toolkit for efficient renovation in buildings.

Building renovation and its connected issues have been presented, and different BIMbased tools have been proposed as solutions to these. The research has been conducted within the context of an ongoing Horizon2020 project, namely BIM4EEB, with the aim to enhance the building process and especially renovation interventions.

Nowadays, there is a strong need to renovate buildings, making them more efficient and more comfortable places where people can live, while also progressing towards the EU objective of decarbonization. BIM-oriented digital tools are seen as the most effective solution for the typical communication and information exchange issues of construction.

The research project gives a contribution to overcome renovation barriers proposing: a tool to speed up the building survey, a tool designed to support the decision-making process enabling the assessment of several energy refurbishment design options; an application for owners and inhabitants to understand their comfort related preferences and non-preferences in building conditions; a tool to improve the HVAC-design, operation and, efficiency management, a tool for fast tracking the renovation activities; an open and interoperable platform to collect data from the other tools and share information between stakeholders.

The developed BIM-based toolkit innovation is related with the adoption of an open interoperable framework which allows the improved exchange of data among the tools and among the stakeholders involved in the different stages of the renovation process.

Information exchange between the tools is based on a set of ontologies developed for renovation and aligned with the most used in AEC, designed for enabling semantic interoperability.

In the future months, the BIM-toolkit will be applied to real and relevant renovation scenarios to validate the proposed methodology. The application of the toolkit in the Demo Cases is useful not only to test the functionalities of the tools, but also to show their applicability and receive a feedback from interested stakeholders.

The developed toolkit can be used in the future for managing renovation works on the relevant number of buildings, built in the last century, that need to improve their performances and quality. The specific interoperability features of the developed toolkit will give a contribution to improve the exchange of data among the different stakeholders involved in the specific stages of the renovation process.

Author Contributions: Conceptualization, B.D. and C.M.B.; methodology, B.D. and C.M.B.; investigation, B.D., C.M.B., S.L.S., A.P., M.S., S.C., C.M., M.N.L., B.A., P.A., A.V., D.M., J.C., D.F., B.O., E.O., F.T., K.M., S.O. (Sinead O'Sullivan), S.O. (Stephen O'Donovan), A.H., D.O.; writing-original draft preparation, B.D., C.M.B., S.L.S., A.P., M.S., S.C., C.M., M.N.L., B.A., P.A., A.V., D.M., J.C., D.F., B.O., E.O., F.T., K.M., S.O. (Sinead O'Sullivan), S.O. (Stephen O'Donovan), A.H., D.O.; writing-review and editing, A.H., D.O. (English review), B.D., C.M.B.; project administration, B.D. All authors have read and agreed to the published version of the manuscript.

Funding: This research received funding from European Commission within Horizon 2020 Framework Programme 820660.

Institutional Review Board Statement: Not applicable.

Informed Consent Statement: Not applicable.

Data Availability Statement: No new data were created or analyzed in this study. Data sharing is not applicable to this article. 
Acknowledgments: The authors thank all the researchers and the companies involved in the BIM4EEB project and the development of the toolkit. This research was funded by BIM4EEB project, grant agreement number 820660, as part of the European Union's Horizon 2020 research and innovation program.

Conflicts of Interest: The authors declare that there is no conflict of interest. The content of this publication reflects only the authors' view, and the funders are not responsible for any use of the information proposed.

\section{References}

1. European Commission Department. Energy Energy Efficiency in Buildings; EC: Brussels, Belgium; Luxembourg, 2020.

2. Digitalisation in the Construction Industry, Build Up-The European Portal for Energy Efficiency in Buildings. 2019. Available online: https:/ / www.buildup.eu/en/news/overview-digitalisation-construction-industry (accessed on 5 May 2021).

3. Zomer, T.; Neely, A.; Sacks, R.; Parlikad, A. Exploring the influence of socio-historical constructs on BIM implementation: An activity theory perspective. Constr. Manag. Econ. 2020, 39, 1-20. [CrossRef]

4. Jacobsson, M.; Linderoth, H.C.J.; Rowlinson, S. The role of industry: An analytical framework to understand ICT transformation within the AEC industry. Constr. Manag. Econ. 2017, 35, 611-626. [CrossRef]

5. Awwad, K.A.; Shibani, A.; Ghostin, M. Exploring the critical success factors influencing BIM level 2 implementation in the UK construction industry: The case of SMEs. Int. J. Constr. Manag. 2020, 1-8. [CrossRef]

6. Ozturk, G.B. Interoperability in building information modeling for AECO/FM industry. Autom. Constr. 2020, 113, 103122. [CrossRef]

7. The British Standards Institution. BS 1192-2007 +A1-2015: Collaborative Production of Architectural, Engineering and Construction Information-Code of Practice; BSI: London, UK, 2015; p. 40.

8. Pauwels, P.; Zhang, S.; Lee, Y.C. Semantic web technologies in AEC industry: A literature overview. Autom. Constr. 2017, 73, 145-165. [CrossRef]

9. European Commission. A Renovation Wave for Europe-Greening Our Buildings, Creating Jobs, Improving Lives; EC: Brussels, Belgium; Luxembourg, 2020.

10. European Commission. Renovation Wave: Doubling the Renovation Rate to Cut Emissions, Boost Recovery and Reduce Energy Poverty; EC: Brussels, Belgium; Luxembourg, 2020.

11. IET and NTU Scaling Up Retrofit 2050. 2018. Available online: www.theiet.org/built-environment\%0Ahttps://www.theiet.org/ factfiles / built-env / retrofit.cfm?type=pdf (accessed on 5 May 2020).

12. D'Oca, S.; Ferrante, A.; Ferrer, C.; Pernetti, R.; Gralka, A.; Sebastian, R.; Op't Veld, P. Technical, financial, and social barriers and challenges in deep building renovation: Integration of lessons learned from the H2020 cluster projects. Buildings 2018, 8, 174. [CrossRef]

13. BPIE. The European Renovation Wave: From Words to Action; BPIE: Brussels, Belgium, 2020.

14. Abanda, F.H.; Tah, J.H.M.; Keivani, R. Trends in built environment Semantic Web applications: Where are we today? Expert Syst. Appl. 2013, 40, 5563-5577. [CrossRef]

15. Barbosa, M.J.; Pauwels, P.; Ferreira, V.; Mateus, L. Towards increased BIM usage for existing building interventions. Struct. Surv. 2016, 34, 168-190. [CrossRef]

16. HESMOS ICT Platform for Holistic Energy Efficiency Simulation and Lifecycle Management of Public Use Facilities, Management Support. 2013. Available online: https:/ / cordis.europa.eu/project/id/260088 (accessed on 15 February 2021).

17. SWIMing Semantic Web for Information Management in Energy Efficient Buildings. 2017. Available online: https://cordis. europa.eu/project/rcn/193469/results/en (accessed on 15 February 2021).

18. STREAMER. Semantics-Driven Design through Geo and Building Information Modelling for Energy-Efficient Buildings Integrated in Mixed-Use Healthcare Districts; EC: Brussels, Belgium; Luxembourg, 2017.

19. Signorini, M.; Lupica Spagnolo, S. Building Renovation Process Map in Private and Public Works to Improve Communication and Data Exchange. IOP Conf. Ser. Mater. Sci. Eng. 2021, 1044, 012012. [CrossRef]

20. EN 16310:2013-Engineering Services-Terminology to Describe Engineering Services for Buildings, Infrastructure and Industrial Facilities. 2013. Available online: https://standards.iteh.ai/catalog/standards/cen/7250e686-1a17-446c-bc6a-754708162070 /en-16310-2013 (accessed on 24 June 2021).

21. BIM4EEB. D2.2 List of Designers' Needs and Requirements for BIM-Based Renovation Processes. Available online: https: // www.bim4eeb-project.eu/media/doc/D2.2.pdf (accessed on 17 February 2021).

22. BIM4EEB. D2.4 List of Service Companies' Needs and Requirements for BIM-Based Renovation Processes. Available online: https:/ / www.bim4eeb-project.eu/media/doc/D2.4.pdf (accessed on 17 February 2021).

23. BIM4EEB. D2.5 List of Owners' and Inhabitants' Needs and Requirements for BIM-Based Renovation Processes. Available online: https:/ / www.bim4eeb-project.eu/media/doc/D2.5.pdf (accessed on 17 February 2021).

24. Toth, Z.; De Groote, M.; De Regel, S.; Carbonari, G.; Calderoni, M.; Ricci, M.; Loureiro, T.; Dourlens-Quaranta, S.; Sterling, R.; Glicker, J.; et al. Building Logbook State of Play; Publications Office of the EU: Luxembourg, 2020.

25. De Regel, S.; Carbonari, G.; Dourlens-Quaranta, S.; Toth, Z.; De Groote, M.; Glicker, J.; Borragán, G.; Volt, J. Definition of the Digital Building Logbook; Publications Office of the EU: Luxembourg, 2020; pp. 1-48. 
26. Curry, E.; O’Donnell, J.; Corry, E.; Hasan, S.; Keane, M.; O’Riain, S. Linking building data in the cloud: Integrating cross-domain building data using linked data. Adv. Eng. Inform. 2013, 27, 206-219. [CrossRef]

27. W3C Building Topology Ontology. Available online: https://w3c-lbd-cg.github.io/bot/ (accessed on 30 December 2020).

28. BuildingSMART ifcOWL: ifcOWL Standard. Available online: https://github.com/buildingSMART/ifcOWL (accessed on 30 December 2020).

29. Idehen, K.U. What Is a SPARQL Endpoint, and Why Is It Important? 2018. Available online: https:/ / medium.com/virtuosoblog/what-is-a-sparql-endpoint-and-why-is-it-important-b3c9e6a20a8b (accessed on 30 December 2020).

30. W3C SPARQL 1.1 Overview. Available online: https:/ /www.w3.org/TR/sparql11-overview/ (accessed on 30 December 2020).

31. Fielding, R.T. Architectural Styles and the Design of Network-Based Software Architectures; University of California: Irvine, CA, USA, 2000.

32. BIM4EEB BIM4EEB BIM Management System. 2020. Available online: https://bim4eeb.oneteam.it/BIMMS/default.aspx. (accessed on 30 December 2020).

33. Oraskari, J. IFCtoLBD: IFCtoLBD Converts IFC (Industry Foundation Classes) STEP Formatted Files into the Linked Building Data Ontologies. Available online: https://github.com/jyrkioraskari/IFCtoLBD (accessed on 30 December 2020).

34. BIM4EEB. D6.2 Methods and Tools for Selecting Devices and Linking Them to the Generic Model. Available online: https: / / www.bim4eeb-project.eu/media/doc/BIM4EEB_D6.2_.pdf (accessed on 17 February 2021).

35. EVO. What Is MEV; Efficiency Valuation Organization (EVO): Washington, DC, USA, 2020.

36. ICP. Stopping MEV Adjustment Abuse; ICP: London, UK, 2014.

37. Project Haystack Project Haystack-Tags. 2020. Available online: https:/ / project-haystack.org/tag (accessed on 30 December 2020).

38. Shemeikka, J.; Vesanen, T.; Hasan, A.; Mätäsniemi, T. Early Stage Energy Refurbishment Assessment Tool for Buildings Using High-End BIM Data: Benefits and Challenges. MDPI Proc. 2021, 65, 28. [CrossRef]

39. Digital Construction Ontology Suite. Available online: https://digitalconstruction.github.io/ (accessed on 30 December 2020).

40. Tzortzopoulos, P.; Kagioglou, M.; Koskela, L. Lean Construction: Core Concepts and New Frontiers; Routeledge: New York, NY, USA, 2020.

41. BIM4EEB DICO Ontologies. 2020. Available online: https:/ / digitalconstruction.github.io/ (accessed on 17 February 2021).

42. Törmä, S.; Kiviniemi, M.; Lavikka, R.; Kousouris, S.; Tsatsakis, K. Towards BIM-Enhanced Renovation Management Tools with Support to Stakeholder Interaction. MDPI Proc. 2020, 65, 15. [CrossRef] 